\title{
PRODUÇÃO DE PAPEL BIODEGRADÁVEL UTILIZANDO FOLHAS DE BANANEIRA
}

\author{
Eloísa Soares de Aquino (UFCG/CDSA) eloisaaquino11@ @otmail.com \\ Lucielly Cristina da Silva (UFCG/CDSA) luciellycristina082@gmail.com \\ Naiara Silva Nascimento (UFCG/CDSA) naiaranascimento03@gmail.com \\ Nicole Lustosa de A. Siqueira (UFCG/CDSA) nicolealustosa@gmail.com
}

\section{Resumo}

Atualmente com o dever indispensável de preservar o meio ambiente deu-se a criação das embalagens biodegradáveis, como um dos inúmeros meios de reduzir os danos causados pela poluição, pelo fato de se degradar com mais facilidade. Com base nisso, foi desenvolvido um experimento com o objetivo de fabricar papel a partir das fibras da folha da bananeira, e com o resultado alcançado confeccionar embalagens biodegradáveis. O papel foi obtido através do cozimento da folha da bananeira com acréscimo de materiais que ajudassem na retirada da fibra, e o dessem impermeabilidade, flexibilidade, resistência e coloração. O processo foi dividido em oito etapas, desde a retirada da folha da bananeira até a secagem do papel. $\mathrm{O}$ resultado obtido foi satisfatório para a produção de embalagens. Portanto, verificou-se que o papel produzido por meio da folha da bananeira é uma alternativa biodegradável para auxiliar a redução da poluição do meio ambiente.

Palavras-Chaves: Embalagem biodegradável; folha de bananeira; sustentabilidade; meio ambiente.

\section{Introdução}

Atualmente, diante da necessidade de conservação do meio ambiente, a utilização de produtos biodegradáveis vem ganhando muita importância, levando em conta sua fácil degradação. Nesse cenário, o biomaterial assume papel indispensável para a preservação do ambiente, prevenindo assim, as gerações futuras.

De acordo com Camargo (2018), os biomateriais são constituídos por matérias-primas de origem agrícola, como plantas fibrosas. São resistentes, impermeáveis, flexíveis, e também biodegradáveis, isto é, podem ser usados na compostagem, ou se descartado, irá se 
decompor naturalmente, isso torna seu processo de fabricação e utilização menos agressivo ao meio ambiente.

Ainda, segundo Camargo (2018), o Brasil é um dos maiores produtores de banana do mundo. A fruta é a mais consumida pelos brasileiros. A bananeira contém uma variedade de subprodutos, como a casca, caule e folhas. A casca é utilizada para fins culinários. Do caule são retiradas as fibras e utilizadas para o artesanato. Mas, até pouco tempo, as folhas das bananeiras eram descartadas e pouco utilizadas. No entanto, uma nova alternativa surge a partir da fabricação de embalagens biodegradáveis feitas com a folha da bananeira para substituir embalagens de plástico que agridem o meio ambiente.

Desta forma, o estudo tem a finalidade de apresentar benefícios através da produção de materiais advindos da folha da bananeira, uma planta rica em fibras, de fácil degradação e baixo custo, proporcionando um novo direcionamento a matéria prima.

\section{Referencial teórico}

\subsection{Definições da embalagem biodegradável}

Segundo Costa (2010), define-se como embalagem biodegradável aquela confeccionada com um material que apresente degradação rápida causada pela luz e pelo calor e, consequentemente, biodegradada por microorganismos e seus resíduos finais não sejam prejudiciais à natureza.

De acordo com Costa (2010) as embalagens biodegradáveis têm um tempo estimado de 18 (dezoito) meses para se decompor totalmente através do processo de oxidação, e apresentam como resultado da biodegradação o dióxido de carbono, a água e a biomassa.

Pode-se entender que a degradação é a ruptura do material em pequenas moléculas, estimuladas por mecanismos ambientais como luz, água, temperatura, oxigênio, entre outros, enquanto a biodegradação é a deterioração decorrente da ação de seres vivos, como bactérias e fungos.

\subsection{A embalagem biodegradável}

Segundo Jhall (2017), as embalagens são compostas a partir de uma matéria prima específica, no entanto a maioria delas utiliza itens de difícil decomposição, levando em consideração que são descartadas em lugares inapropriados após o uso, ocasionando a poluição e danos ao ecossistema inteiro. 
Jhall (2017) ainda afirma que para minimizar este problema, alavanca-se a criação das embalagens biodegradáveis, considerando que sua confecção é advinda de insumos orgânicos, como cascas de frutas e verduras, papéis texturizados, e fibras de plantas e árvores. A utilização desse tipo de materiais torna-se favorável ao meio ambiente visto que sua fabricação possibilita fácil decomposição quando expostas a recursos naturais responsáveis por essa fase. Sabendo que o mercado da produção das embalagens biodegradáveis ainda é apoucado bem como a utilização das mesmas, torna-se importante elevar as vantagens que esse tipo de material disponibiliza aos seres vivos, e ao planeta.

\subsection{A importância da biodegradabilidade}

Atualmente, no Brasil, são descartados 105 milhões de toneladas de lixo sólido por ano, o que é cerca de 1 tonelada por habitante/ano, segundo dados do IBGE (Instituto Brasileiro de Geografia e Estatística). A maior parte desse lixo é descartado em lixões e aterros, sendo essencial que ocorra a sua degradação.

Quando o material não é biodegradável, ele não pode fornecer energia aos microorganismos, e consequentemente, não são degradados. Materiais como metais, vidros e cerâmicos podem até sofrer uma lenta ação química por parte da natureza, mas ocasionalmente sofrem ataque direto dos microorganismos.

Outro importante motivo para o impedimento da degradação de alguns materiais é a sua toxicidade. Muitas substâncias impedem o crescimento dos microorganismos, levando esses compostos a ficarem dispersos na natureza.

\subsection{Biodegradação do papel}

A composição do papel consiste basicamente dos polissacarídeos: celulose, lignina e hemicelulose. A partir da quebra das enzimas ocorre a ação dos microorganismos, ou seja, sucede a biodegradação do papel.

Segundo Mendonça (2003, p. 32 apud Rees 1980) a degradação da celulose em condições anaeróbicas transcorre de acordo com celulases - grupo responsável pela hidrolise da celulose em celobiose e glicose - é um conjunto de enzimas que danifica e reduz a celulose com liberação de açúcar. A atuação dos microorganismos converte esses produtos em valerato, butirato, propianato, acetato, etanol e hidrogênio que gera gás e metano.

A hemicelulose possui massa molecular menor comparado com a da celulose, consequentemente consegui se degradar por microorganismo rapidamente, porém necessita de 
um grupo mais complexo de enzimas por possuir uma maior variedade de monômeros (MENDONÇA, 2003, p. 33).

Por outro lado, a lignina é de difícil decomposição, visto que apresenta maior resistência em condições anaeróbias. Portanto intrica a degradação da celulose quando ligada a ela, ou seja, papeis com menor porcentagem de lignina consegue se degradar mais facilmente.

\subsection{Vantagens e desvantagens do material biodegradável}

Tem como vantagem o pouco tempo de permanência no ambiente, o que diminui a chance de efeitos nocivos, como sufocamentos, entrada na cadeia alimentar, contaminação por disruptores, e outros.

Produtos com agentes biodegradáveis mais demorados podem ser inseridos em aterros sanitários e o gás oriundo da decomposição pode ser utilizado para produzir calor e energia, possuem vantagem de deterioração completa e rápida, diminuindo a aglomeração de lixo no planeta e o impacto ao ambiente.

Em contrapartida, o material biodegradável gera uma considerável contribuição para o efeito estufa, porque sua degradação libera gás metano correspondente a velocidade de decomposição, portanto quanto mais ágio a decomposição, maior é a liberação do gás ofensivo.

\section{Materiais e métodos}

\subsection{Produção do papel}

Para a confecção do papel biodegradável, utilizou-se a folha da bananeira, que é descartada assim que os cachos da banana são colhidos. Nesse experimento foram utilizadas as folhas da banana prata, que é a mais comum na região do brejo da Paraíba.

A pesquisa foi realizada na cidade de Sumé - PB, elaborada de forma bibliográfica e qualitativa, sendo desempenhada a partir de registros científicos disponíveis a exames. Refere-se a uma análise experimental, visto que o objetivo de estudo foi determinado e selecionada possíveis variáveis com intuito de chegar à meta estabelecida que consiste em confeccionar embalagens biodegradáveis. Foram realizados três experimentos, e o terceiro foi o que apresentou características ideais para a realização do objetivo de estudo, devido a sua confecção, onde houve o acréscimo de produtos que melhorassem as falhas dos experimentos anteriores. 
Existem dois tipos de processos para a produção do papel: o mecânico e o químico. $\mathrm{O}$ primeiro faz a utilização de prensas mecânicas e o segundo faz uso de produtos químicos. Esta experiência desfrutou do segundo processo.

O experimento escolhido para a fabricação da embalagem utiliza os seguintes materiais:

- Folha de bananeira, em um tamanho de $10 \mathrm{~cm}$ x $10 \mathrm{~cm}$;

- Soda cáustica;

- Barrilha, pó utilizado para balancear o pH das piscinas;

- ColaCMC, cola comestível;

- Tesoura;

- Peneira;

- Luvas;

- Água sanitária;

- Bacia com capacidade para 5L;

- Anilina em gel comestível;

- Peneira $25 \mathrm{~cm}$ x $15 \mathrm{~cm}$;

- Madeira prensada 22,5 cm x 12,5 cm;

- Recipiente de zinco com capacidade para 12L;

- Peneira $45 \mathrm{~cm}$ x $40 \mathrm{~cm}$;

- Liquidificador com capacidade para 1,5L;

- Bacia com capacidade para $15 \mathrm{~L}$.

Na primeira etapa da experiência utilizaram-se as folhas da bananeira, que foram extraídas, limpas e cortadas com o auxílio de uma tesoura em um tamanho de $10 \mathrm{~cm}$ x $10 \mathrm{~cm}$. Nesta etapa são usadas apenas as partes mais macias da folha, sem fazer uso do talo.

A etapa II compreende a parte do cozimento das folhas. Em um recipiente de zinco, são adicionados $8 \mathrm{~L}$ de água (capacidade para submergir todas as folhas), 1/2 colher de sobremesa de soda cáustica aplicada para ajudar no amolecimento das fibras, 8 colheres de sopa de barrilha ( 1 colher para cada litro de água) para controlar o $\mathrm{pH}$ das folhas, pois sem o auxílio da barrilha, ao final do cozimento a água ficará com um $\mathrm{pH}$ muito alto e pode agredir ao meio ambiente se for descartada de forma incorreta. Em seguida adicionam-se as folhas cortadas. Nessa etapa é importante a utilização de máscaras e luvas devido à soda cáustica que é um produto tóxico. $\mathrm{O}$ cozimento é realizo em fogo alto, aproximadamente $280^{\circ}$. Após começar a 
ferver, é necessário ficar mexendo o conteúdo para que não derrame. Leva-se em torno de 2 a 5 horas de cozimento, e sabe-se que está pronta quando a folha começa a se desmanchar. Após o cozimento dá-se início a III etapa, que abrange os processos de lavagem das folhas. Depois de cozidas, elas são retiradas e colocadas em uma peneira, lavadas em água corrente para ser retirada a soda cáustica, e em seguida, espremidas e colocadas numa bacia. Repetir o processo duas vezes.

Na IV etapa realiza-se a quebra das fibras. Após serem lavadas, as folhas são colocadas em pouca quantidade no liquidificador com $250 \mathrm{~mL}$ de água e processadas por cerca de 2 minutos. As fibras devem estar bem finas e separadas. Após o processamento é necessário repetir a etapa III, utilizando a peneira mais fina, já que as fibras agora estão em um tamanho menor.

$\mathrm{Na} \mathrm{V}$ etapa efetua-se a descoloração das fibras. Em uma bacia adiciona-se 2,5L de água e 4 colheres de sopa de água sanitária, após a mistura pronta acrescentam-se as fibras já lavadas e deixa em repouso por cerca de $2 \mathrm{~h}$. Após a solução agir sobre as fibras, elas são retiradas e repete-se a etapa III.

A coloração das fibras ocorre na VI etapa. Em uma bacia são adicionados $2 \mathrm{~L}$ de água e diluída 1 colher de chá de anilina em gel. Após a diluição da anilina acrescentam-se as fibras e deixa em repouso por $5 \mathrm{~h}$. Durante esse período é importante mexer, para que as fibras não se unam e absorvam melhor a cor.

Em outro recipiente prepara-se a cola CMC. Para cada 1,5L de água é colocada 1 colher de sopa do pó $\mathrm{CMC}$, liquidificada por no mínimo 1 minuto, e posta em repouso por 6 horas.

Para dar início a VII etapa, onde ocorre a pescagem das fibras, acrescenta-se 1 copo de 250 $\mathrm{mL}$ de cola $\mathrm{CMC}$ a mistura que estava em repouso na etapa anterior. Efetua-se a pescagem com o auxílio de uma peneira. Após as fibras estarem bem distribuídas na peneira coloca-se a madeira prensada e com a ajuda de um pano sob o chão prensa-se a peneira para retirar ao máximo o excesso de água.

Na VIII etapa ocorre a secagem. As peneiras são colocadas para secar ao sol, até que sequem totalmente. Não é recomendado retirar o papel da peneira antes da secagem, podendo ocorrer o encolhimento ou engilhamento do papel.

Após a secagem, o papel estará pronto para uso. Na Figura 1 encontra-se o fluxograma com todas etapas envolvidas para a fabricação do papel. 
Figura 1 - Etapas da fabricação do papel

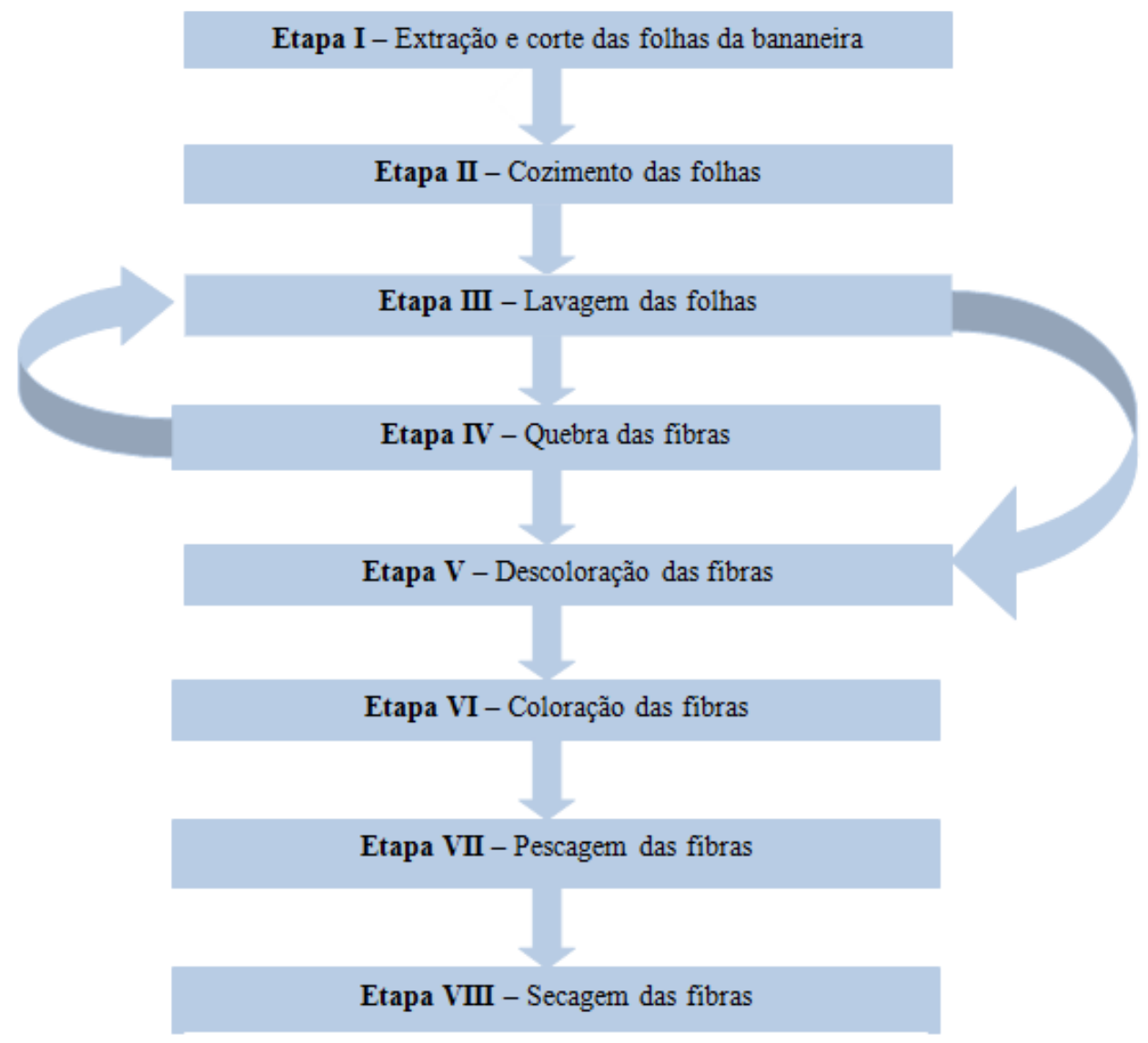

Fonte: Autoria própria (2018)

\section{Resultados e discussões}

Observou-se que na primeira experiência da confecção do papel apenas com a fibra da folha da bananeira que se encontrava já no estado ressecado, foi obtido uma folha flexível, resistente e com uma superfície áspera.

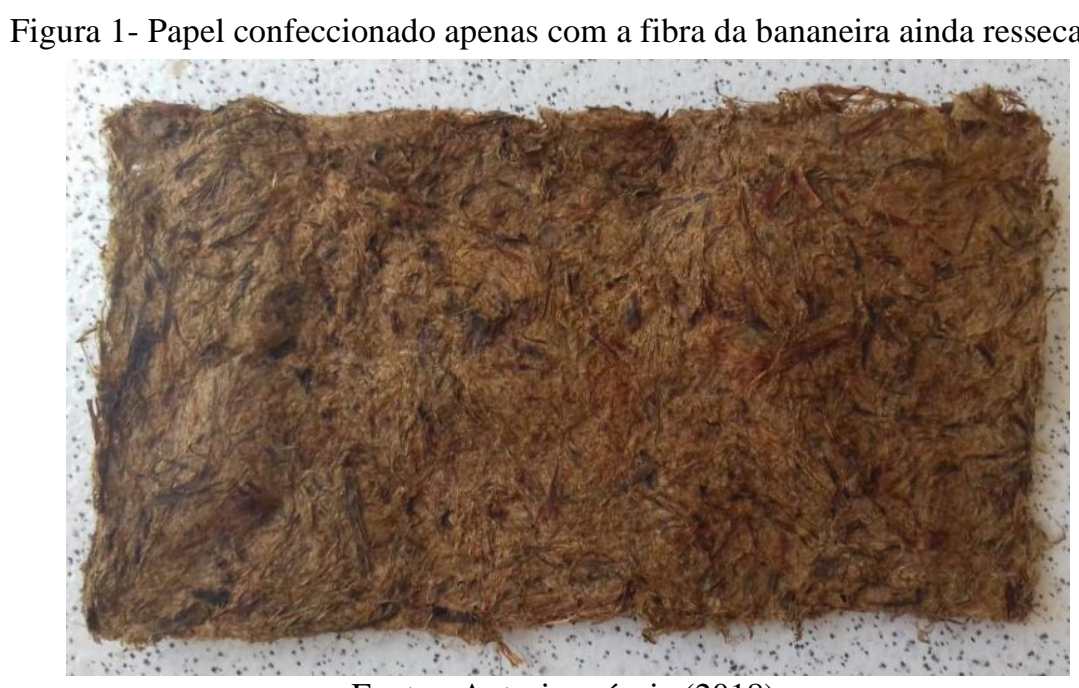

Fonte - Autoria própria (2018) 
Na segunda experiência observou-se que a confecção do papel apenas com a fibra da folha da bananeira ainda verde e com pouco tempo de cozimento, obteve-se um papel flexível, não resistente e poroso.

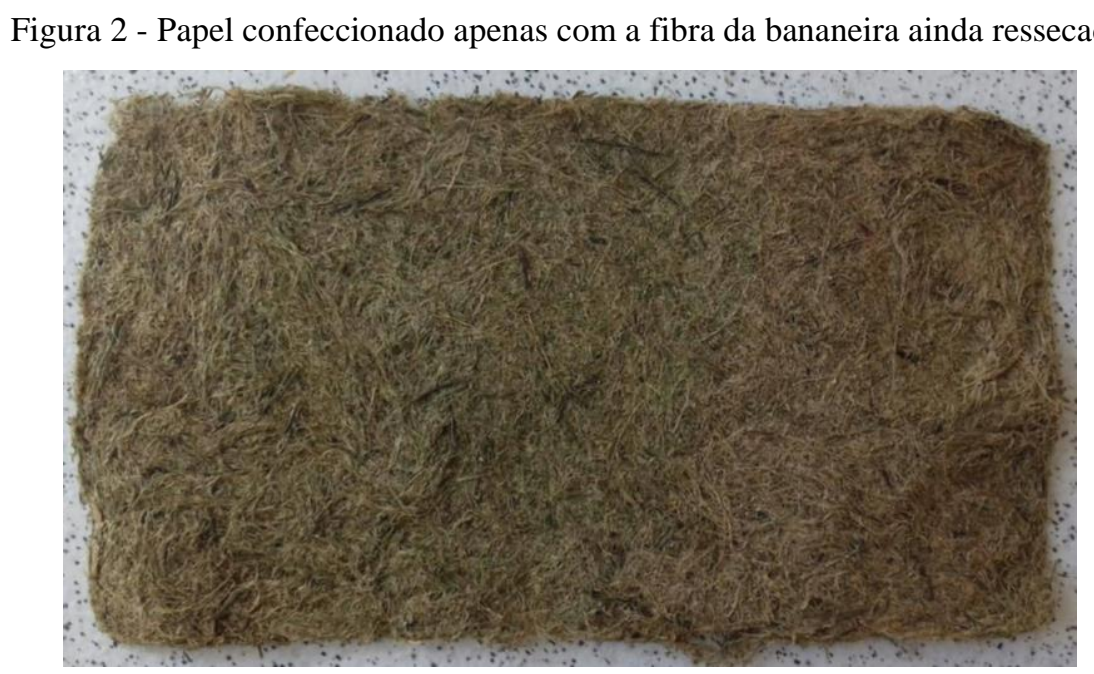

Fonte - Autoria própria (2018)

Na terceira e última experiência observou-se que a confecção do papel através da folha da bananeira ainda verde e o acréscimo de barrilha e soda cáustica para o amolecimento das fibras, água sanitária para o descoloramento das mesmas, anilina para colorir e cola CMC para dar impermeabilidade, obtém-se uma folha de papel resistente, uniforme, compacta, flexível e colorida.

Figura 3 -Papel confeccionado com a fibra da folha da bananeira e acréscimo de materiais, sem coloração do lado esquerdo e com coloração do lado direito
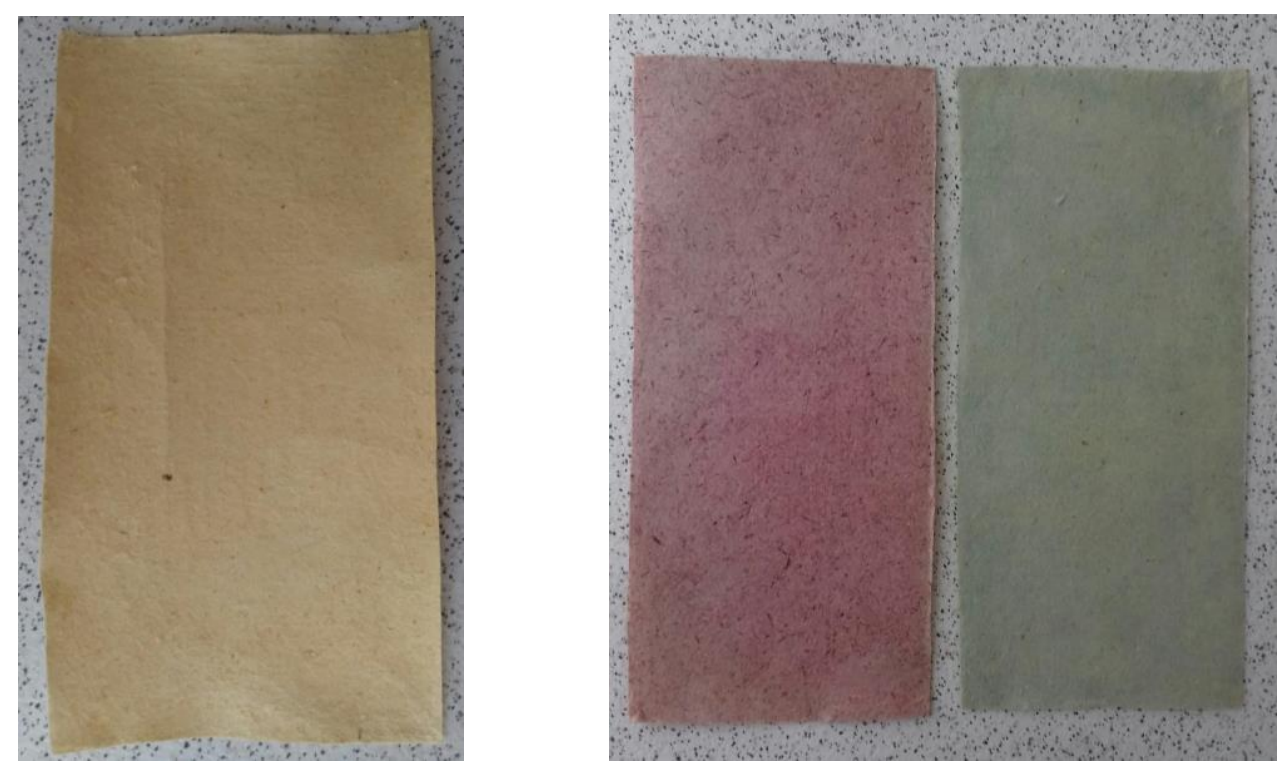

Fonte: Autoria própria (2018) 


\section{Considerações finais}

Todos os esforços para o desenvolvimento sustentável têm como objetivo suprir as necessidades da geração atual, sem comprometer a capacidade de atender as necessidades das futuras gerações. Isto implica em buscar meios ecologicamente corretos de produção de bens e serviços de forma que não degrade o meio ambiente.

A folha da bananeira possui em sua composição microestrutural um alto percentual das microfibrilas de celulose que possuem fácil degradação, conduzindo a bons resultados nos experimentos. Evidenciou-se que os processos de fabricação do papel artesanal, influenciam nas características finais do mesmo, como cor, textura, maleabilidade e espessura. Assim, a confecção da embalagem depende integralmente de que não ocorra nenhum erro na produção do papel.

O material confeccionado no experimento feito a partir da folha de bananeira é uma ótima opção para se utilizar no lugar das embalagens plásticas, uma vez que se degrada mais facilmente por ser um material biodegradável sendo também sustentável ao meio ambiente.

\section{Referências bibliográficas}

CAMARGO, Suzana - Folha de bananeira é alternativa natural e sustentável a embalagens e papel alumínio. 2018. Disponível em: <http://conexaoplaneta.com.br/blog/folha-de-bananeira-e-alternativa-natural-esustentavel-embalagens-e-papel-aluminio/> Acesso em: 24 de junho de 2016.

COSTA, Nilmara Matias - Embalagens biodegradáveis. 2010. Disponível em:

<http://www.ebah.com.br/content/ABAAABuVkAK/embalagens-biodegradaveis> Acesso em: 12 de julho de 2018.

IBGE - Instituto Brasileiro de Geografia e Estatística. (2016). Senso cidades. Disponível em: <https://cidades.ibge.gov.br/brasil> Acesso em: 20 de julho de 2018.

JHALL, Anthony - Exemplos de embalagens biodegradáveis e suas principais vantagens. 2017. Disponível em: 〈https://www.fragmaq.com.br/blog/exemplos-de-embalagens-biodegradaveis-e-suas-principais-vantagens/> Acesso em: 20 de julho de 2018.

MENDONÇA, Jucélia Cabral. Influência da tinta de impressão na digestão anaeróbia do papel jornal. 2003. 149f. Dissertação (Mestre em Engenharia Civil na área de Ciências da Engenharia Ambiental) - Escola de Engenharia de São Carlos Unidade de São Paulo, São Carlos, 2003. 